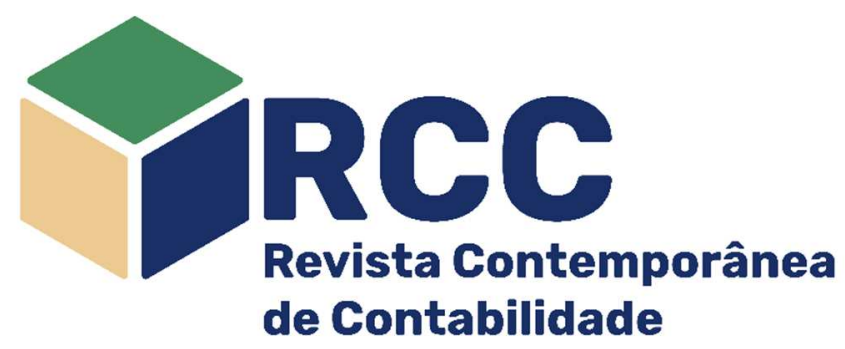

\title{
A influência da accountability na capacidade estatal, na alocação dos recursos públicos e no desenvolvimento socioeconômico em municípios brasileiros
}

The accountability influence on state capacity, allocation of public resources and socioeconomic development in Brazilian municipalities

La influencia de la responsabilidad en la capacidad del estado, la asignación de recursos públicos y el desarrollo socioeconómico en los municipios brasileños

\author{
Wesley de Almeida Mendes* \\ Doutor em Administração (UFV), Viçosa/MG, Brasil \\ wesleytstcerest@gmail.com \\ https://orcid.org/0000-0001-6443-2572 (1)
}

Marco Aurélio Marques Ferreira Doutor em Economia Aplicada (UFV) Professor no Departamento de Administração e Contabilidade (UFV) Viçosa/MG, Brasil marcoaurelio@ufv.br https://orcid.org/0000-0002-9538-1699

Endereço do contato principal para correspondência*
Av. Peter Henry Rolfs, s. n., Campus Universitário, CEP: $36570-000$, Viçosa/MG, Brasil

\begin{abstract}
Resumo
O artigo teve por objetivo verificar a influência da accountability e da capacidade estatal na alocação dos recursos públicos e no desenvolvimento socioeconômico em municípios brasileiros. Ao adotar a capacidade estatal como um interveniente dessa relação, forma-se um sistema em que se entende que a accountability (no conceito geral), e o controle (de forma específica), influenciam a capacidade municipal. Esta, por sua vez, elabora o orçamento e aplica os recursos atendendo tanto a legislação fiscal, quanto a demanda social e, assim, gera resultados positivos para a sociedade. Para tanto, foi elaborado um índice de Capacidade Municipal a partir de uma análise fatorial e aplicado sobre a Modelagem de Equações Estruturais. Os resultados, assim, provam que a capacidade é influenciada pela accountability e influencia a alocação dos recursos públicos.
\end{abstract}

Palavras-chave: Accountability; Capacidade Estatal; Controle

\begin{abstract}
The article aimed to verify the influence of accountability and state capacity in the allocation of public resources and socioeconomic development in Brazilian municipalities. By adopting state capacity as an intervener in this relationship, a system is formed in which accountability (in the general concept) and control (in a specific way) are understood to influence municipal capacity. The latter, in turn, prepares the budget and invests the resources in compliance with both tax legislation and social demand and, thus, generates positive results for society. For that, a Municipal Capacity Index was elaborated from a factor analysis and applied on the Structural Equation Modeling. The results thus prove that capacity is influenced by accountability and influences the allocation of public resources.

Keywords: Accountability; State Capacity; Control

\section{Resumen}

El artículo tuvo como objetivo verificar la influencia de la rendición de cuentas y la capacidad estatal en la asignación de recursos públicos y el desarrollo socioeconómico en los municipios brasileños. Al adoptar la capacidad del estado como interviniente en esta relación, se forma un sistema en el que se entiende que la responsabilidad (en el concepto general) y el control (de una manera específica) influyen en la capacidad municipal. Este último, a su vez, prepara el presupuesto e invierte los recursos de conformidad con la legislación fiscal y la demanda social y, por lo tanto, genera resultados positivos para la sociedad. Para eso, se elaboró un Índice de capacidad municipal a partir de un análisis factorial y se aplicó en el Modelo de
\end{abstract}


ecuaciones estructurales. Los resultados demuestran que la capacidad está influenciada por la rendición de cuentas e influye en la asignación de recursos públicos.

Palabras clave: Responsabilidad; Capacidad del estado; Control

\section{Introdução}

Os municípios brasileiros, dotados de autonomia política e administrativa, necessitam conciliar as demandas sociais e sua capacidade estatal. Essa conciliação visa a formulação e implementação de políticas públicas em busca da manutenção do estado e do bem-estar da população. A fim de compreender o conceito da capacidade estatal, diversos conceitos foram desenvolvidos (Pires \& Gomide, 2016; Guillén \& Capron, 2016; Rogers \& Weller, 2014; Gibler \& Miller, 2014), os quais tornaram fontes para o entendimento para este estudo, consistida como um conjunto de habilidades e competências - políticas e administrativas necessárias à formulação de metas, à alocação de recursos, aos esforços e à implementação de ações para 0 alcance dos resultados almejados.

Para tanto, como destaca Cingolani (2013), a capacidade estatal envolve elementos políticos e burocráticos para os diversos pontos que a compõem, entre eles os aspectos legal, coercitivo e fiscal, sendo este relacionado à capacidade de arrecadação. Nesse sentido, a capacidade estatal está atrelada ao volume de recursos arrecadados, considerando sua necessidade para a manutenção do Estado e a implementação de políticas públicas (Leon-Moreta, 2017).

Contudo, é importante verificar que, diante da configuração do modelo federativo brasileiro, os municípios consistem no ente federado com menor volume de arrecadação (Baião, Cunha, \& Souza, 2017). Dessa forma, os municípios com baixa atividade econômica e de pequeno porte possuem dificuldades de arrecadação e realização de investimentos, mesmo com os repasses dos demais entes federados (LeonMoreta, 2017). Essa situação amplia a limitação da capacidade estatal, uma vez que as metas fiscais estabelecidas pela Constituição Federal de 1988 e pela legislação vigente deverão ser condizentes com o volume de recursos disponíveis.

Ao mesmo tempo que as metas devem ser proporcionais aos recursos disponíveis, a legislação estabelece condições para sua aplicação. Assim, se por um lado há os esforços da capacidade estatal para atender as demandas com foco no alcance dos resultados planejados, por outro há a necessidade de cumprir a legislação fiscal.

Nesse sentido, a conciliação entre a capacidade estatal com a demanda social e o cumprimento da legislação fiscal se torna complexa. As normas fiscais têm por finalidade a manutenção do equilíbrio das contas públicas, tentando garantir, mesmo que os recursos sejam escassos e as necessidades sociais sejam crescentes, a saúde financeira do município.

Assim, visando auxiliar essa manutenção, surgem os mecanismos de controle. Esses mecanismos partem da abordagem da Accountability, que visa monitorar as atividades da gestão, estabelecendo condições à capacidade estatal e à alocação dos recursos públicos.

Destaca que a accountability ocorre de diversas formas. Podem ser considerados os modelos horizontal (com utilização de mecanismos de controle estatais, dotados de conhecimento técnico) e vertical (com base no processo eleitoral). Além desses, há ainda o modelo social, ou societal, no qual as ações do Estado são controladas por organismos da sociedade civil e outras entidades.

Mesmo com as diferentes formas de atuação dos mecanismos de controle, é importante entender que suas ações devem ocorrer em conjunto. Há, por um lado, os órgãos técnicos estabelecidos, tais como poder legislativo, tribunais de contas e ministério público, por exemplo, dotados de conhecimentos técnicos enquanto, por outro lado, tem-se a sociedade que corresponde ao principal interessado nas ações do Estado, sendo diretamente afetada pela sua ação ou omissão, cabendo a ela sua atuação no processo eleitoral e nos controles sociais fora do período eleitoral, apresentando demandas e verificando a qualidade dos serviços prestados (O'donnell, 1994).

Assim, diante do exposto, a presente pesquisa tem por objetivo verificar a influência da accountability e da capacidade estatal na alocação dos recursos públicos e no desenvolvimento socioeconômico em municípios brasileiros. Este estudo tomará os municípios de Minas Gerais como objeto, considerando a crise econômica que ele passou durante a década de 2010, que limitou os repasses de recursos estaduais para os municípios, bem como o grande volume de municípios presentes no estado (853), sendo que sua grande maioria $(55,92 \%)$ possui menos de 10 mil habitantes, o que pode reduzir a arrecadação municipal

Diversos estudos visaram analisar a influência da capacidade estatal na gestão pública, seja pela implementação de políticas, seja na condução do governo (Grin et al., 2018; Souza, 2017; Asadullah \& Savoia, 2018; Gomide \& Pires, 2014; Gibler \& Miller, 2014; Pires \& Gomide, 2016). Outros visaram analisar os efeitos da accountability sobre o desempenho da gestão pública (Brinkerhoff \& Wetterberg, 2015; Sell et al., 2018; Justice, Melitski \& Smith, 2006).

Desses estudos, pôde-se notar que o desempenho da gestão pública depende da capacidade estatal do município e da accountability, considerando a atuação dos mecanismos de controle. Assim, o presente estudo busca avançar na literatura ao investigar como os elementos de controle da accountability se 
relacionam com a capacidade municipal, considerando as diferentes formas de atuação da accountability de forma a promover o desempenho na alocação dos recursos públicos municipais.

\section{Referencial Teórico}

\subsection{Capacidade estatal como influenciador das ações públicas}

As ações de alocação dos recursos públicos para o desenvolvimento do Estado perpassam pela capacidade estatal e pela qualidade dos gastos realizados, considerando o desempenho e o controle do governo para atender os limites mínimos de aplicação.

A ideia de capacidade estatal nasce de duas abordagens. A primeira surge na década de 1960, preocupando-se com a autonomia estatal e reconhecendo o Estado como um ator na estabilização das relações entre capital e trabalho, pautado em um modelo mais macro ou exógeno da visão do Estado, preocupado com a resolução de conflitos entre grupos governamentais e não-governamentais e na construção dos aparatos governamentais. A segunda surge entre as décadas de 1970 e 1980 e toma como base abordagens de modelos burocráticos, a qual duas características se tornam centrais: a importância de um poder coercitivo de uma administração central e a formação profissional do servidor público. Esta segunda refere-se à uma abordagem micro e endógena, considerando a presença de especialistas, recursos financeiros e organizacionais na implementação de políticas públicas; em outras palavras, concentra-se no "Estado em ação" (Pires \& Gomide, 2016; Cingolani, 2013).

A partir dessas abordagens da capacidade estatal, diversas conceituações foram utilizadas (Asadullah \& Savoia, 2018; Guillén \& Caprón, 2016; Pires \& Gomide, 2016; Silva, 2015; Gibler \& Miller, 2014; Roger \& Weller, 2014; Huerta, 2008; Fukuyama, 2004). Para o presente estudo, a capacidade estatal será tratada como o conjunto de elementos burocráticos, que envolvem as habilidades e competências políticas e administrativas na formulação de metas, na alocação de recursos, nos esforços e na implementação de políticas para o alcance dos resultados planejados.

A importância de se tratar a capacidade estatal está em considerar que as vontades dos agentes públicos não são suficientes para alcançar os objetivos, sendo necessária a complementação por mecanismos capazes de viabilizar as ações do Estado (Souza, 2017). No Brasil, com a promulgação da Constituição Federal de 1988 e as reformas administrativas para controle econômico e fiscal, o ambiente da administração pública tornou-se complexo devido ao incremento do aparato burocrático e político.

Nesse período houve ampliação da legislação e das instituições de controle, destacando-se a importância da accountability como instrumento influenciador da capacidade estatal. Essa ampliação pode ser vista dentro do discurso de Grindle (1996), ao retratar, na dimensão institucional da capacidade estatal, o conceito de accountability.

Assim, a accountability corresponde tanto ao aspecto de ações internas da gestão pública (relacionado à prestação de contas, transparência e responsividade) quanto pelo aspecto de ações externas (como o controle e responsabilização do ator público). Logo, o discurso de accountability como elemento da capacidade institucional, descrito por Grindle (1996), parte das ações internas da gestão pública, cabendo aos órgãos externos o controle horizontal, vertical e social.

No Brasil, os aspectos de ações externas da accountability no Brasil ganham força a partir da década de 1990, com a remodelação da arquitetura institucional, considerando as disputas de interesse dentro do campo social, político, burocrático e econômico. Tal fato e, em especial a exigência de garantias de solvência fiscal imposta por fundos internacionais, culminou, em 2000, na criação da Lei de Responsabilidade Fiscal (LRF), que focou em elementos de controle e responsabilização do ator público que utiliza recursos financeiros para suas atividades.

Com o orçamento público delimitado por instrumentos legais, o modelo de coalizão política se torna um importante instrumento para conseguir apoios para tomadas de decisão política, tendo em vista que 0 orçamento público é avaliado e votado por políticos presentes nas câmaras legislativas.

Dessa forma, as decisões tomadas pelos gestores nem sempre correspondem às ideias iniciais, mas são resultados de uma relação política, exigindo dos líderes a capacidade para lidar com esses grupos de interesse, sendo uma questão central da capacidade política a habilidade de formar frentes às situações de atrito (Gaitán \& Boschi, 2016). Essas discussões entre diversos parlamentares de partidos diferentes, burocratas dos diferentes poderes, grupos da sociedade civil, entre outros, demandam arranjos institucionais específicos (Pires \& Gomide, 2016).

Nesse sentido, considerando os diferentes atores envolvidos na capacidade estatal, os instrumentos de accountability e controle não podem se limitar apenas em elementos técnicos e regimentares, mas devem envolver elementos políticos e sociais. Ressalta-se, assim, o papel de cada forma de controle, buscando direcionar a capacidade do Estado e suas competências de forma a ampliar a atendimento dos serviços públicos.

Essa relação política-administrativa como influenciadora da capacidade estatal não foi observada apenas no contexto brasileiro, mas em outros ambientes que visavam mecanismos democráticos para gestão, uma vez que ambientes autocráticos enfraqueciam a capacidade estatal em formular políticas públicas e 
diminuiriam o processo de desenvolvimento dos países (Knutsen, 2013; Ward, Cao, \& Mukherjee, 2014).

Nesse sentido, para entender a capacidade estatal é importante que se considere o conjunto de relações burocráticas e políticas que cercam o processo de gestão, bem como o controle da burocracia como forma a atender as necessidades da sociedade.

\subsection{0 sistema de alocação dos recursos públicos}

A presente pesquisa foi estruturada considerando um sistema de influência na alocação dos recursos públicos. Tal sistema parte da premissa que, para a manutenção do Estado, é necessário que possua disponibilidade de recursos, sejam eles humanos ou financeiros. Para tanto, Alesina e Perotti (1999) alertam que o orçamento público não seja restritivo, uma vez que os serviços públicos necessitam de recursos para sua implementação.

Embora seja necessário que a aplicação seja realizada de forma eficiente, a restrição de recursos pode comprometer a oferta de serviços públicos e o avanço do desenvolvimento humano (Mendes et al., 2018). Conforme Oliveira e Araújo (2019), os recursos públicos não podem ser utilizados de qualquer forma, sem planejamento, uma vez que pode comprometer na manutenção no atendimento às demandas sociais, como saúde, educação e renda.

Tal fato atribui ao Estado a necessidade de atentar-se à função distributiva como papel a ser atendido. entende-se que, a partir da contribuição financeira de todos os indivíduos, realizada a partir do recolhimento de tributos, o Estado torna-se capaz de aplicar esses recursos para gerar políticas públicas que possuem benefícios gerais, seja de forma direta ou indireta (Musgrave, 1959).

Assim, reconhece a existência de desigualdade entre os municípios, bem como considera que o orçamento público deve formar um instrumento de planejamento, distribuindo os recursos recolhidos de forma a priorizar a necessidade fiscal, a fim de minimizar essas diferenças (Baião et al., 2017). Em outras palavras, pela função distributiva, elementos de características socioeconômicas são consideradas, de forma a promover o desenvolvimento local, em suas múltiplas dimensões, tais como descritas por Sen (2010), com destaque para a saúde, a educação e o emprego e renda.

Nesse sentido, tanto a Constituição Federal de 1988 quanto a legislação fiscal, estabeleceram limites mínimos de recursos a serem gastos com saúde e educação, com o objetivo de, ao buscar o equilíbrio fiscal, áreas de desenvolvimento social não sejam prejudicadas com cortes de recursos e, consequentemente, reduzam sua qualidade ao longo dos anos.

Essa relação entre recursos públicos e economia influenciando o desenvolvimento humano foi discutido por Mendes et al. (2018) que identificaram que os recursos arrecadados pelo município e aqueles provenientes de transferências, além do PIB fracionado por Indústria, Agropecuária e Serviços, possuem influências positivas sobre o desenvolvimento humano, destacando o papel da disponibilidade de receitas na promoção das condições socioeconômicas, em especial Saúde, Educação e Emprego e renda, mensurados pelo IFDM.

Essas transferências de recursos são fontes de receita não própria que o sistema federado possui, podendo ser tanto já estabelecido pela legislação quanto por interesse do agente político em distribuir esse recurso.

Assim, para que o administrador público e o governo consigam criar força política na aplicação do plano de governo e cumprimento das normas estabelecidas pela legislação, torna-se necessária a criação de parcerias entre agentes políticos, a fim de manter a governabilidade e a atração de recursos (Pires \& Gomide, 2016).

O Estado, Nesse Sentido, Deve Realizar Esforços Administrativos (gerenciando problemas e recursos) e políticos (identificando o papel de cada ator eletivo na construção, manutenção e melhorias do bem-estar da sociedade). Para essas atuações, Grindle (1996) as categorizou como dimensões administrativa e política da capacidade estatal. Contudo, é importante destacar que elas não ocorrem de forma isolada, pelo contrário, estão sempre atreladas uma à outra.

A relação entre as dimensões administrativa e política pode ser intensificada, ao considerar que os municípios, por serem o ente federado com menor volume de arrecadação e, consequentemente, menor força de atração de servidores com maiores níveis de capacitação técnica, necessitam de apoio do estado e da União para complemento de seus recursos e manutenção da máquina pública. Assim, de forma a ampliar esses recursos, os atores políticos criam alianças nas diferentes esferas e poderes do Estado.

Essas alianças ocorrem em um sistema de coalizão, interação de interesses de diferentes atores, que visa alcançar um determinado objetivo, sendo no campo público, o desenvolvimento de interesse público (Gaitán \& Boschi, 2016). Se por um lado essa interação eleva a força do governante, por outro exige a atuação da accountability e seus elementos de controle para minimizar os riscos da má gestão, sejam por meios sociais (desde os controles sociais, econômicos e de organizações sem fins lucrativos), sejam de mecanismos estatais de controle (considerando o poder legislativo, o ministério público e o tribunal de contas).

Para Arantes et al. (2010), o controle consiste em um elemento da accountability com objetivo de tentar garantir que os agentes públicos e políticos atuem como representantes do povo. A accountability visa compreender as finalidades e os envolvidos das ações públicas que são realizadas (Holzer \& Schwester, 
2011), bem como reconhecer as responsabilidades dos agentes públicos por essas ações.

Para compreender a accountability, duas abordagens são predominantes: a Horizontal e a Vertical (O'donnell, 1994). Enquanto a accountability horizontal consiste em mecanismos de avaliação e controle desempenhados por entidades de mesmo nível, relativos às redes formadas por instituições autônomas, capazes de indicar caminhos ou mesmo punir seus iguais, baseados por regras e normas formais, o modelo Vertical tem como base o processo eleitoral como forma de controle e aprovação das ações públicas realizadas.

O controle Horizontal no Brasil ganhou força após a promulgação da LRF em 2000, onde estabeleceu o papel de cada ente federado em executar os recursos, bem como dos Tribunais de Contas e poder legislativo em fiscalizar essa execução. Rocha (2013) indica que, devido a natureza autônoma dos Tribunais de Contas, esses se tornaram o que deveria ser exemplo de instrumento de accountability.

Smulovitz e Peruzzotti (2000) apresentaram uma terceira abordagem para completar aquelas descritas por O'Donnel (1994), denominada accountability social. Essa terceira perspectiva considera que a accountability vertical tem grande foco no processo eleitoral, assim a accountability social tentou dar foco nas ações sociais de controle com base em organizações, associações e outras formas de união da sociedade visando a melhoria das ações públicas (Smulovitz \& Peruzzotti, 2000). Ali e Pirog (2019) sugerem que a accountability social tem mais influência nas políticas públicas quando a voz do cidadão e a capacidade estatal de ouvi-la se reforçarem mutuamente.

Nesse sentido, enquanto o controle por mecanismos técnicos, baseado na accountability horizontal, possui capacidade física e humana para identificar falhas no processo de gestão e no descumprimento da legislação vigente (Arantes et al., 2010), o controle social, da mídia e de outros organismos não governamentais, baseado na accountability Social, utiliza da sua capacidade de reconhecimento de demandas e, por estar mais próximo do problema, consegue observar a execução das ações públicas (Smulovitz \& Peruzzotti, 2000; Ali \& Pirog, 2019).

A accountability Social abrange o monitoramento e supervisão do cidadão nos setores públicos e privados, o sistema de acesso e disseminação de informações públicas centradas no usuário, mecanismos públicos de reparação de queixas e reclamações, bem como a participação do cidadão nas tomadas de decisões sobre a alocação dos recursos (Fox, 2015). Conforme Chasukwa, Chiweza e Chikapa-Jamali (2014), o controle social pode ser entendido como um avanço do contexto eleitoral, permitindo ao cidadão que auxilie nas tomadas de decisões e na cobrança por melhorias da gestão. Por outro lado, esses mecanismos podem ser falhos, destacando a superficialidade em que sejam tratados os temas bem como as barreiras encontradas para que as tomadas de decisões ocorram de fato (Magalhães \& Xavier, 2019; Chasukwa et al., 2014) com discussões pouco proveitosas para o controle da gestão, tentativas de coerções, falta de tempo para aprofundamento do debate e barreiras nas deliberações.

Esses mecanismos de controle, tanto social quanto estatal, juntamente com a capacidade estatal, direcionam esforços para que os recursos sejam alocados conforme a necessidade social sem, no entanto, desviar das prerrogativas previstas pela legislação vigente.

Conforme expressam Brinkerhoff e Wetterberg (2015), a accountability, em especial a accountability social, reflete o desempenho e a forma como ocorre a alocação dos recursos públicos. A capacidade estatal se insere neste modelo como um conciliador entre a demanda por recursos e a sua disponibilidade. Como expõem Pires e Gomide (2016), Guillén e Caprón (2016) e Rogers e Weller (2014), a capacidade estatal corresponde à habilidade do estado em alcançar metas, conforme os recursos disponíveis. É a "ponte" entre o que está disponível para a gestão pública e a forma como isso será aplicado para alcançar os resultados que visam o benefício social.

Além da alocação dos recursos, é importante que se analise sua forma de distribuição, de modo a promover a melhoria das condições socioeconômicas. Nesse caso, tanto a necessidade fiscal influencia a forma como os recursos serão distribuídos pelos municípios, quanto a própria alocação desses recursos tende a promover melhorias nas condições socioeconômicas, sendo essa sua finalidade ao optar por realizar distribuições divergentes, priorizando municípios com menores níveis de desenvolvimento socioeconômico.

Diante do exposto, é possível considerar as decisões para alocação dos recursos como um sistema complexo, com diversas interações em que as ações políticas e gerenciais se relacionam de forma a direcionar os recursos, enquanto a capacidade estatal atua como um instrumento no centro do sistema que regula as operações, expandindo ou limitando as ações a serem tomadas e influenciando diretamente nos resultados a serem encontrados. Além disso, os mecanismos de controle visam a adequação dos recursos aplicados para o cumprimento de metas legais e políticas adotadas em agendas e programas de governo.

\section{Procedimentos Metodológicos}

\subsection{Coleta de dados}

Para atender o objetivo proposto, tomou-se os 853 municípios de Minas Gerais como indivíduos para as análises estatísticas, dos quais apenas 412 municípios consistiram para a amostra devido a ausência de dados disponíveis para os demais indivíduos. 
Todos os dados foram coletados de fontes secundárias. Para os dados do TRE-MG correspondem aos dados do resultado eleitoral de 2012 (para eleições municipais e identificação do partido dos vereadores e prefeitos eleitos) e 2014 (para eleições estaduais e federal, para identificação do partido dos deputados, senadores e chefes do executivo eleitos).

A receita bruta e a alocação dos recursos públicos foram coletadas da base de dados do FINBRA, disponibilizada pelo site do Tesouro Nacional. Para a análise do corpo burocrático dos municípios, os dados foram consultados a base MUNIC do IBGE, nos anos de 2014 e 2015, visto que algumas dessas variáveis só estava disponível para um desses anos analisados.

Para as variáveis que compuseram o "controle horizontal", foram realizadas análises individuais dos relatórios de contas de governo dos municípios, que tinham transcritos os pareceres dos técnicos, do ministério público de contas e do plenário do TCE-MG. Os resultados dos julgamentos dos plenários das câmaras municipais, também foram disponibilizados pelo site do TCE-MG.

Os dados de controle social foram coletados na base IMRS. O controle vertical consistiu do confronto entre a eleição de 2008 e 2012 (ambos em pleito municipal), com a possibilidade de verificar a reeleição de prefeito ou partido, ambos coletados do site do Tribunal Regional Eleitoral - Minas Gerais.

Todas as variáveis correspondem ao ano de 2015, exceto as variáveis cuja base consiste em dados do TRE (uma vez que são dados da eleição municipal) e as variáveis Servidor instruído e assessoria, cuja base de dado mais recente corresponde ao ano de 2014. A escolha do período se deve pela disponibilidade do conjunto de dados que contemplasse, em maior quantidade, os constructos de capacidade estatal, accountability, alocação de recursos e desenvolvimento.

\subsection{Criação do Índice de Capacidade Estatal}

A princípio, foi realizado um índice de Capacidade para os municípios mineiros. Para a criação desse índice, os dados coletados foram disponíveis por ferramentas eletrônicas oficiais do governo, sendo investigados sobre um conjunto de dimensões, descritas na Figura 1. Apesar de defasadas, comparadas com as demais variáveis, optou-se por utilizá-las, tendo em vista que a variação de 1 ano pode ser baixa, e a ausência dessas variáveis podem não contemplar o máximo da realidade municipal.

Para a construção desse índice, foi realizada uma análise fatorial exploratória, cujo objetivo dessa análise é encontrar uma relação entre as variáveis capaz de reduzi-las em um conjunto menor de variáveis estatísticas (fatores), com a menor perda de informação (Marôco, 2006; Hair Jr. et al., 2009). Devida as diferentes escalas adotadas, para o procedimento de análise fatorial, as variáveis foram padronizadas, em score-z, de forma que estivessem em uma mesma escala com média 0 e desvio padrão igual a 1.

Com a análise fatorial foram extraídos os escores fatoriais para serem utilizados na construção do indicador de capacidade e, em seguida foram transformados os escores para que fiquem no mesmo quadrante (Sabioni et al, 2016), utilizando a equação:

$$
F_{I J}=\frac{\left(F-F_{\min }\right)}{\left(F_{\max }-F_{\min }\right)}
$$

Em que $F_{\text {min }}$ e $F_{\text {máx }}$ são as cargas fatoriais mínimas e máximas observadas, respectivamente, para os municípios mineiros. A construção do indicador utilizou a equação em que se agregam os $p$ fatores obtidos:

$$
\text { Capacidade }_{j}=\frac{\sum_{j=1}^{k} p_{i} F_{i j}}{\sum p i}(1)
$$

Em que, cada indicador é o índice para o i-ésimo município, p é o número de fatores extraídos na análise, ij é o índice para o j-ésimo município, pié o peso da i-ésima variável, $F_{j i}$ é a carga fatorial do i-ésimo fator para o j-ésimo município. K é o número de municípios. Todos os indicadores foram parametrizados, de forma que o valor mais alto receba nota 1 e os demais sejam proporcionais à maior nota como sugerem Sabioni et al. (2016). As variáveis estão apresentadas na Figura 1.

As variáveis referentes aos políticos consideraram o resultado eleitoral, mesmo que não fosse do ano de 2015, uma vez que a legislatura estaria vigente em 2015. Já os dados relacionados à instrução dos servidores e assessoria só foram divulgados pelo IBGE para o ano de 2014. Por considerar que as ações do ano anterior ainda refletem as atuações do ano corrente, bem como a diferença de 1 ano poder ser mínima.

\subsection{Análise do sistema de relações pela Modelagem de Equações Estruturais}

Após criado o índice de capacidade, foi estimado um Modelo de equações estruturais (SEM) em Path Analysis, cujo conjunto de variáveis pode ser observado na Figura 2. 


\begin{tabular}{|c|c|c|c|c|}
\hline Variável & Descrição & Ano & Base & Fonte \\
\hline $\begin{array}{l}\text { Razão partido } \\
\text { Câmara estadual }\end{array}$ & $\begin{array}{l}\text { Razão do número de deputados estaduais do mesmo partido do } \\
\text { prefeito, pelo número total de deputados estaduais ( } 77 \text { eleitos) }\end{array}$ & $\begin{array}{l}2012 / \\
2014\end{array}$ & \multirow{5}{*}{$\begin{array}{l}\text { Gaitán e } \\
\text { Boschi } \\
\text { (2016) }\end{array}$} & TRE - MG \\
\hline $\begin{array}{l}\text { Razão coligação } \\
\text { Câmara estadual }\end{array}$ & $\begin{array}{l}\text { Razão do número de deputados estaduais pertencentes à } \\
\text { mesma coligação da qual o partido do prefeito faz parte, pelo } \\
\text { número total de deputados estaduais ( } 77 \text { eleitos) }\end{array}$ & $\begin{array}{l}2012 / \\
2014\end{array}$ & & TRE - MG \\
\hline $\begin{array}{l}\text { Razão partido } \\
\text { Câmara fed }\end{array}$ & $\begin{array}{l}\text { Razão do número de deputados federais eleitos em Minas Gerais } \\
\text { filiados ao mesmo partido do prefeito, pelo número total de } \\
\text { deputados federais de Minas Gerais ( } 53 \text { eleitos) }\end{array}$ & $\begin{array}{l}2012 / \\
2014\end{array}$ & & TRE - MG \\
\hline $\begin{array}{l}\text { Razão coligação } \\
\text { Câmara fed }\end{array}$ & $\begin{array}{l}\text { Razão do número de deputados federais eleitos em Minas Gerais } \\
\text { pertencentes à mesma coligação da qual o partido do prefeito faz } \\
\text { parte, pelo número total de deputados federais de Minas Gerais } \\
\text { (53 eleitos) }\end{array}$ & $\begin{array}{l}2012 / \\
2014\end{array}$ & & TRE - MG \\
\hline $\begin{array}{l}\text { Receita Bruta Per } \\
\text { capita }\end{array}$ & $\begin{array}{l}\text { Proporção da receita de arrecadação própria dividido pelo } \\
\text { volume populacional registrado pelo IBGE em logaritmo natural. }\end{array}$ & 2015 & & Tes. Nac. \\
\hline $\begin{array}{l}\text { Funcionários per } \\
\text { capita }\end{array}$ & $\begin{array}{l}\text { Proporção de servidores na administração pública municipal pelo } \\
\text { volume populacional registrado pelo IBGE }\end{array}$ & 2015 & \multirow{5}{*}{$\begin{array}{l}\text { Grin et al. } \\
(2018)\end{array}$} & $\begin{array}{l}\text { MUNIC } \\
\text { IBGE }\end{array}$ \\
\hline $\begin{array}{l}\text { Atividades } \\
\text { terceirizadas }\end{array}$ & $\begin{array}{l}\text { Escala somada pelas variáveis binárias sobre a contratação de } \\
\text { atividades terceirizadas, mesmo que parcialmente, dos serviços } \\
\text { de coleta de resíduo sólido domiciliar, coleta de resíduo sólido } \\
\text { hospitalar, coleta de resíduo sólido industrial, limpeza nas } \\
\text { unidades prediais da administração municipal, limpeza urbana, } \\
\text { segurança das unidades prediais da administração municipal e } \\
\text { iluminação pública, sendo, para cada uma dessas variáveis } 1 \\
\text { para contratado e } 0 \text { para o contrário, podendo a escala assumir } \\
\text { de } 0 \text { a } 7 \text { pontos }\end{array}$ & 2015 & & $\begin{array}{l}\text { MUNIC } \\
\text { IBGE }\end{array}$ \\
\hline Taxas & $\begin{array}{l}\text { Escala somada pelas variáveis binárias sobre a cobrança de } \\
\text { taxas, sendo essas taxas sobre a iluminação pública, coleta de } \\
\text { lixo, incêndio ou combate a sinistros, limpeza urbana, poder de } \\
\text { polícia e outros tipos de taxas, sendo, para cada uma dessas } \\
\text { variáveis } 1 \text { para cobrança e } 0 \text { para o contrário, podendo a escala } \\
\text { assumir de } 0 \text { a } 6 \text { pontos }\end{array}$ & 2015 & & $\begin{array}{l}\text { MUNIC } \\
\text { IBGE }\end{array}$ \\
\hline Consórcios & $\begin{array}{l}\text { Escala somada pelas variáveis binárias sobre a articulação } \\
\text { interinstitucional, considerando a participação em consórcio nas } \\
\text { áreas de educação, saúde, assistência e desenvolvimento social, } \\
\text { turismo, cultura, habitação, transporte, meio ambiente, } \\
\text { desenvolvimento urbano, saneamento básico, gestão das águas } \\
\text { e manejo de resíduos sólidos, sendo, para cada uma dessas } \\
\text { variáveis } 1 \text { para participa e } 0 \text { para o contrário, podendo a escala } \\
\text { assumir de } 0 \text { a } 12 \text { pontos }\end{array}$ & 2015 & & $\begin{array}{l}\text { MUNIC } \\
\text { IBGE }\end{array}$ \\
\hline Servidor Instruído & $\begin{array}{l}\text { Número de servidores com pelo menos ensino fundamental } \\
\text { completo dividido pelo número total de servidores }\end{array}$ & 2014 & & $\begin{array}{l}\text { MUNIC } \\
\text { IBGE }\end{array}$ \\
\hline Assessoria & $\begin{array}{l}\text { Escala somada pelas variáveis binárias sobre a contratação de } \\
\text { assessoria, considerando para realizar atividades para a } \\
\text { contratação de funcionários, para realizar atividades para } \\
\text { pagamento de funcionários, jurídica, contábil/financeira, } \\
\text { cartográfica e para elaboração de projetos para a captação de } \\
\text { recursos, sendo, para cada uma dessas variáveis } 1 \text { para possui } \\
\text { e } 0 \text { para o contrário, podendo a escala assumir de } 0 \text { a } 6 \text { pontos }\end{array}$ & 2014 & \multirow{4}{*}{$\begin{array}{l}\text { Grin et al. } \\
(2018)\end{array}$} & $\begin{array}{l}\text { MUNIC } \\
\text { IBGE }\end{array}$ \\
\hline $\begin{array}{l}\text { Atividades } \\
\text { informatizadas }\end{array}$ & $\begin{array}{l}\text { Escala somada pelas variáveis binárias sobre as atividades } \\
\text { informatizadas, considerando cadastro e/ou banco de dados da } \\
\text { saúde, educação, patrimônio, funcionários, execução } \\
\text { orçamentária e folha de pagamento, sendo, para cada uma } \\
\text { dessas variáveis } 1 \text { para possui e } 0 \text { para o contrário, podendo a } \\
\text { escala assumir de } 0 \text { a } 6 \text { pontos - MUNIC }\end{array}$ & 2015 & & $\begin{array}{l}\text { MUNIC } \\
\text { IBGE }\end{array}$ \\
\hline $\begin{array}{l}\text { Salário médio } \\
\text { anual }\end{array}$ & $\begin{array}{l}\text { Despesa anual com gastos com pessoal, disponibilizada pelo } \\
\text { TCE, dividida pelo número total de servidores, disponibilizado } \\
\text { pelo IBGE na pesquisa MUNIC. Em logaritmo natural. }\end{array}$ & 2015 & & $\begin{array}{c}\text { MUNIC } \\
\text { IBGE/ TCE }\end{array}$ \\
\hline $\begin{array}{l}\text { Legislação } \\
\text { planejamento } \\
\text { municipal }\end{array}$ & $\begin{array}{l}\text { Escala somada pelas variáveis binárias sobre a existência de } \\
\text { instrumentos legais de planejamento urbano, considerando } \\
\text { legislação sobre área e/ou zona especial de interesse social, } \\
\text { zona e/ou área de especial interesse, perímetro urbano, } \\
\text { parcelamento do solo, zoneamento ou uso e ocupação do solo, } \\
\text { solo criado ou outorga onerosa do direito de construir, } \\
\text { contribuição de melhoria, operação urbana consorciada, estudo } \\
\text { de impacto de vizinhança, código de obras, legislação sobre } \\
\text { zoneamento ambiental ou zoneamento ecológico, servidão } \\
\text { administrativa, tombamento, unidade de conservação, uso } \\
\text { especial para fins de moradia, usucapião especial de imóvel } \\
\text { urbano, direito de superfície, regulação fundiária, legitimação de } \\
\text { posse e estudo prévio de impacto ambiental, sendo, para cada } \\
\text { uma dessas variáveis } 1 \text { para possui e } 0 \text { para o contrário, podendo } \\
\text { a escala assumir de } 0 \text { a } 20 \text { pontos }\end{array}$ & 2015 & & $\begin{array}{l}\text { MUNIC } \\
\text { IBGE }\end{array}$ \\
\hline
\end{tabular}

Figura 1: Variáveis aplicadas para construção do índice de capacidade

Fonte: Elaborado pelo autor. 


\begin{tabular}{|c|c|c|c|}
\hline Variável & Descrição & Ano & Fonte \\
\hline Capacidade & $\begin{array}{l}\text { Indicador de capacidade estatal dos municípios mineiros, variando de } 0 \text { a } \\
1 \text { em que quanto mais próximo de } 1 \text { maior a capacidade. }\end{array}$ & 2015 & $\begin{array}{l}\text { Resultados da } \\
\text { pesquisa }\end{array}$ \\
\hline Controle Horizontal & $\begin{array}{l}\text { Escala somada pelas variáveis binária sobre a aprovação e reprovação } \\
\text { das contas municipais pelo órgão técnico do TCE, Plenário do TCE, } \\
\text { Ministério Público de Contas e poder legislativo municipal, sendo, para } \\
\text { cada uma dessas variáveis } 1 \text { para aprovado e } 0 \text { para o contrário, podendo } \\
\text { a escala assumir de } 0 \text { a } 4 \text { pontos }\end{array}$ & 2015 & $\begin{array}{l}\text { MPC e TCE } \\
\text { MG }\end{array}$ \\
\hline Controle Social & $\begin{array}{l}\text { Escala somada pelas variáveis binárias sobre a existência de conselhos } \\
\text { municipais de políticas públicas em atividade de esporte, saúde, } \\
\text { educação, cultura, segurança alimentar, defesa dos direitos de crianças e } \\
\text { adolescentes, idoso, pessoa com deficiência e saneamento ou afim sendo, } \\
\text { para cada uma dessas variáveis } 1 \text { para possui e } 0 \text { para o contrário, } \\
\text { podendo a escala assumir de } 0 \text { a } 9 \text { pontos }\end{array}$ & $2015^{\star}$ & IMRS \\
\hline Controle Vertical & $\begin{array}{l}\text { Escala somada pelas variáveis binárias sobre a reeleição do poder } \\
\text { executivo, considerando a reeleição do prefeito e a reeleição do partido, } \\
\text { para cada uma dessas variáveis } 1 \text { para reeleito e } 0 \text { para o contrário, } \\
\text { podendo a escala assumir de } 0 \text { a } 2 \text { pontos }\end{array}$ & $\begin{array}{l}2012 / \\
2008\end{array}$ & TRE \\
\hline $\begin{array}{l}\text { Alocação dos recursos } \\
\text { públicos }\end{array}$ & $\begin{array}{l}\text { Somatório dos gastos per capita com saúde e gastos com educação, } \\
\text { logaritmo natural. }\end{array}$ & 2015 & $\begin{array}{l}\text { Tesouro } \\
\text { Nacional } \\
\end{array}$ \\
\hline PIB municipal & $\begin{array}{l}\text { Razão do valor total do PIB produzido pelo município, em } \mathrm{R} \$ 1,00 \text {, pela } \\
\text { população, logaritmo natural. }\end{array}$ & 2015 & IBGE \\
\hline Saúde & Índice FIRJAN de Desenvolvimento Municipal no contexto Saúde & 2016 & FIRJAN \\
\hline Educação & Índice FIRJAN de Desenvolvimento Municipal no contexto Educação & 2016 & FIRJAN \\
\hline Emprego & $\begin{array}{l}\text { Índice FIRJAN de Desenvolvimento Municipal no contexto Emprego e } \\
\text { renda }\end{array}$ & 2016 & FIRJAN \\
\hline
\end{tabular}

Figura 2: Variáveis aplicadas no modelo

Nota: * variável dummy de conselho de pessoa com deficiência e saneamento foi registrada para o ano de 2014. Fonte: Elaborado pelo autor.

Essa técnica é empregada para testar a validade de modelos teóricos que definem relações causais entre as variáveis (Marôco, 2010). É uma técnica que se fundamenta nos modelos de regressão linear múltipla e de análise fatorial, mas se difere delas por verificar relações de dependência mútua e interrelações entre as variáveis (Hair Jr. et al., 2009). Para a execução da SEM, todas as variáveis e coeficientes foram padronizados, a fim de equalizar medidas.

Considerando que o desenvolvimento é observado em dimensões (quais sejam saúde, educação, emprego, renda, saneamento, entre outros), cujos resultados são sensíveis a indicadores após um determinado período após as ações de políticas públicas, como expõe Sen (2010), os indicadores de Saúde, Educação e Emprego e renda utilizados nos estudos foram aqueles coletados para o ano de 2016.

A utilização de variáveis defasadas para justificar condições socioeconômicas pode ser observado em Bernardo, Almeida e Nascimento (2020) e Oliveira e Araújo (2019), que utilizaram variáveis de período anterior para explicar a condição socioeconômica e o desenvolvimento dos municípios.

A Figura 3 consiste no diagrama de caminhos do modelo de equações estruturais proposto, cujos caminhos e os sinais correspondem às hipóteses a serem testadas. Os $\varepsilon$ correspondem aos erros da estimação. A validação do modelo ocorrerá por diversos indicadores, sendo considerado o conjunto proposto por Acock (2013.



Figura 3: diagrama de caminho

Fonte: Elaborado pelo autor

Para as medidas absolutas de ajustamento, foram utilizados os testes Qui-quadrado sobre graus de 
liberdade ( $\mathrm{X}^{2} / \mathrm{GL}$ ) e de Root Mean Square Error of Approximation (RMSEA). Já para as medidas comparativas de ajustamento, aplicaram-se os testes de Tucker-Lewis Index (TLI) e o Comparative Fit Index (CFI). Por fim, foi realizado o teste de raiz quadrada da média dos quadrados dos erros de aproximação (SRMR) para as medidas de parcimônia.

\section{Resultados e Discussões}

Dos 853 municípios de Minas Gerais, 588 foram objeto deste estudo, por terem dados disponíveis para o ano em estudo, sendo para eles calculado o índice de Capacidade Municipal. Contudo, dos municípios analisados, apenas as câmaras legislativas de 412 realizaram, até abril de 2019, o julgamento das contas. Pela ausência de julgamento da conta no plenário da câmara municipal, a variável Controle Horizontal, calculada como uma escala somada das decisões do TCE, Câmara municipal, Ministério público de contas e técnicos do tribunal de contas, obteve 412 observações. A estatística descritiva pode ser observada na Tabela 1.

A partir dessas variáveis, a fim de obter uma proxy de capacidade estatal, foi realizada uma análise fatorial, cuja medida de adequação da amostragem $\mathrm{KMO}$ foi de 0.602 , confirmando a sua adequação. Foram extraídos 6 fatores relacionados à capacidade estatal, sendo seles a Capacidade Política, Capacidade Administrativa, Planejamento, Cooperação, Instrução e Apoio Burocrático.

Após extraídos os Fatores, foi estabelecido o índice de Capacidade. Assim, considerou-se conjuntamente os fatores Capacidade política, capacidade administrativa, planejamento, relações institucionais, instrução e apoio burocrático em um índice e classificou-se os municípios de Minas Gerais conforme sua capacidade. De forma a compreender a distribuição do Índice de Capacidade, os valores foram reparametrizados, considerando o maior valor como 1. O valor mínimo do índice encontrado corresponde ao município Chalé, um município com índice de desenvolvimento (IFDM) com valor de 0,697 e PIB per capita de $\mathrm{R} \$ 10184,73$, enquanto o município com maior valor corresponde ao município de Araporã, com PIB per capita de $\mathrm{R} \$ 206730,62$ e índice de desenvolvimento (IFDM) de 0,813 , o qual é considerado valor alto de desenvolvimento.

Após calculado o índice de Capacidade, foi realizada a técnica de Modelagem de Equações Estruturais em path analysis. Os testes de adequação do modelo validaram sua qualidade, como pode ser observado na Tabela 2, e apresentou Coeficiente de determinação $\left(R^{2}\right)$ de 0,510 . Esse coeficiente indica que as variáveis adotadas tem poder de explicação de $51 \%$, o que demonstra a importância delas para orientar políticas e ações no setor público com potenciais efeitos sobre as variáveis de respostas.

Tabela 1:

Estatística descritiva das variáveis aplicadas nos modelos fatorial e SEM

\begin{tabular}{|c|c|c|c|c|c|}
\hline & & Mínimo & Máximo & Média & Desvio padrão \\
\hline \multirow{14}{*}{$\begin{array}{l}\text { Criação do } \\
\text { Índice de } \\
\text { Capacidade }\end{array}$} & $\begin{array}{l}\text { Razão partido Câmara } \\
\text { estadual }\end{array}$ & 0,000 & 0,130 & 0,074 & 0,045 \\
\hline & $\begin{array}{l}\text { Razão coligação Câmara } \\
\text { estadual }\end{array}$ & 0,013 & 0,299 & 0,210 & 0,109 \\
\hline & Razão partido Câmara fed & 0,000 & 0,189 & 0,085 & 0,058 \\
\hline & $\begin{array}{l}\text { Razão coligação Câmara } \\
\text { fed }\end{array}$ & 0,000 & 0,396 & 0,287 & 0,146 \\
\hline & $\begin{array}{l}\text { Receita Bruta Per capita } \\
2015\end{array}$ & 1482,518 & 12195,169 & 2851,084 & 1235,324 \\
\hline & Funcionários per capita & 0,000 & 0,157 & 0,032 & 0,018 \\
\hline & Atividades terceirizadas & 0,000 & 7,000 & 1,998 & 1,181 \\
\hline & Taxas & 0,000 & 6,000 & 2,743 & 1,317 \\
\hline & Consórcios & 0,000 & 12,000 & 1,974 & 1,787 \\
\hline & Servidor Instruído & 0,000 & 1,000 & 0,979 & 0,065 \\
\hline & Assessoria & 0,000 & 5,000 & 2,221 & 0,909 \\
\hline & Atividades informatizadas & 0,000 & 1,000 & 0,993 & 0,082 \\
\hline & Salário médio anual & 2966,849 & 34123,406 & 14715,534 & 4353,826 \\
\hline & Leg. planejamento municipal & 0,000 & 20,000 & 5,828 & 4,458 \\
\hline \multirow{8}{*}{ SEM } & Controle Social & 0,000 & 9,000 & 4,257 & 1,338 \\
\hline & Controle Horizontal & 1,000 & 4,000 & 3,524 & 0,900 \\
\hline & Controle Vertical & 0,000 & 2,000 & 0,461 & 0,727 \\
\hline & PIB 2015 & 5083,579 & 206730,600 & 14942,510 & 12844,830 \\
\hline & $\begin{array}{l}\text { Alocação dos recursos } \\
\text { públicos }\end{array}$ & 610,265 & 4468,468 & 1263,972 & 442,194 \\
\hline & Educação 2016 & 0,603 & 0,947 & 0,810 & 0,053 \\
\hline & Saúde 2016 & 0,357 & 0,972 & 0,767 & 0,109 \\
\hline & Emprego e Renda 2016 & 0,208 & 0,747 & 0,436 & 0,100 \\
\hline
\end{tabular}

Fonte: dados da pesquisa

Os coeficientes estimados do modelo foram descritos na Figura 4. Devido a não normalidade das variáveis, Acock (2013) recomenda a estimação por erros padrões robustos, o que foi realizado. Diante dos resultados, é possível perceber que a Capacidade estatal do município é influenciada por mecanismos de 
controle Social e Vertical.

Tabela 2:

Índices de ajustamento do modelo

\begin{tabular}{ccc}
\hline Critérios & Parâmetros Desejáveis & Modelo Sugerido \\
\hline $\mathrm{X}^{2}$ & - & 17,572 \\
\hline g.I. & - & 14,000 \\
\hline $\mathrm{X} 2 /$ g.I. & $\leq 5,000$ & 1,255 \\
\hline $\mathrm{CFI}$ & $\geq 0,800$ & 0,991 \\
\hline TLI & $\geq 0,900$ & 0,981 \\
\hline SRMR & $\leq 0,080$ & 0,022 \\
\hline RMSEA & $\leq 0,080$ & 0,025
\end{tabular}

Nota: Parâmetros com base em Hair Jr. et al. (2009), Marôco (2010) e Acock (2013).

Fonte: dados da pesquisa.

O fato de a capacidade municipal ser influenciada pela força da sociedade, tanto pelo poder de voto quanto pela avaliação do processo governamental, pode ser explicada por Gaitán e Boschi (2016), segundo os quais a capacidade estatal necessita de coalizões, sejam entre grupos sociais ou políticos e econômicos para buscar o desenvolvimento.

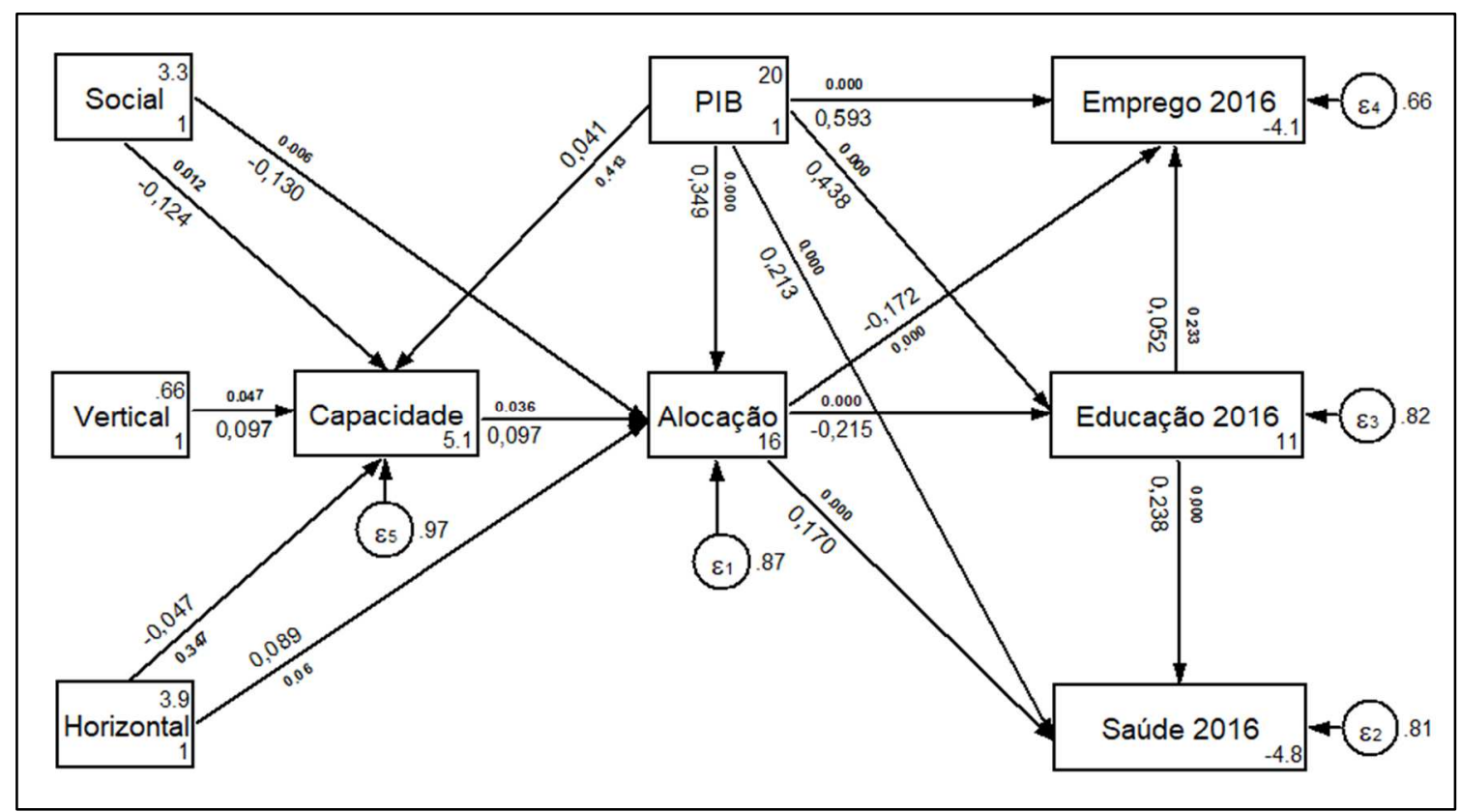

Figura 4: diagrama de caminho com modelo estimado

Nota: Nas retas estão presentes o coeficiente estimado (em fonte maior) e o p-valor (em fonte menor). Os $\varepsilon$ correspondem ao erro aleatório. Nas variáveis estão a média estimada (no canto superior direito) e a variância estimada (no canto inferior direito)

Fonte: Elaborado pelo autor

Ainda, considerando que ambos os modelos de Controle Social e Vertical, correspondem às ações sociais frente ao governo, nota-se que a democracia é um importante instrumento para influenciar a Capacidade da gestão pública. Conforme Ali e Pirog (2019), a atuação da população tende a promover a melhoria dos serviços públicos, uma vez que agem sobre os problemas que os afetam diretamente.

Contudo, os modelos de Controle apresentaram influências divergentes. Enquanto Vertical se mostra positivo, podendo ser interpretado tanto pela manutenção da estrutura política que anteriormente governava, quanto pela influência nas relações na capacidade política, uma das dimensões da capacidade estatal, a social se mostra de forma inversa.

Essa relação inversa com a capacidade pode ser compreendida pela incapacidade da gestão pública municipal em responder a população. Fox (2015) associa a accountability social como uma relação de "voz" e "dente", sendo a voz a situação de a sociedade transmitir seus interesses aos órgãos públicos, e o dente a capacidade de resposta do estado às vozes. Por não atender em completude os interesses públicos, os dentes podem corresponder ao fato do "corte", da "mordida", que pode ser doloroso para a população. Além disso, como destacam Chasukwa et al. (2014) e Magalhães e Xavier (2019), os sistemas de controle podem apresentar falta de articulação dos membros, tentativas de coerções e barreiras nas deliberações, enfraquecendo as pautas decisórias e o papel desses mecanismos.

Assim, pode-se entender que, diante do cenário brasileiro, em específico dos municípios mineiros, o estado não consegue atender as "vozes" apresentadas pela população, apresentando dificuldades de suprir 
as demandas apresentadas. Já o fato de a relação de Controle Horizontal e capacidade não ter apresentado significância estatística pode ser explicado devido à natureza do controle horizontal, que ocorre sobre o cumprimento da legislação em relação aos gastos públicos. Arantes et al. (2010) informam ainda a dificuldade de os mecanismos de controle atuarem sobre a burocracia e a política estatal, elementos que compõem a mensuração da capacidade estatal.

Assim, entendendo que a accountability atua com ações internas de prestação de contas, e ações externas de controle, nota-se que as ações da sociedade são mais incisivas sobre o agente público. Tal fato ocorre devido ao poder da sociedade em escolher o agente político a exercer um mandato eletivo e, consequentemente, seu plano de governo. Além disso, por ser o principal interessado pela boa aplicação dos recursos, suas implicações podem ir além do cumprimento da legislação fiscal (medida adotada por mecanismos horizontais), mas para a boa aplicação e/ou o atendimento das necessidades da população.

Nota-se que a variável Capacidade do município exerce influência positiva e significativa a nível de $5 \%$ na alocação dos recursos com gastos sociais. Tal situação confirma a relação proposta no diagrama de caminhos e indica que, quanto maior a capacidade do município, maior será o investimento realizado para fins sociais, em especial com saúde e educação. Além disso, a maior atuação do Controle Horizontal tem efeito positivo sobre os gastos sociais. Considerando que os mecanismos de controle horizontal possuem influência sobre a prestação de contas públicas, bem como a Constituição Federal de 1988 estabeleceu limites mínimos de gastos com saúde e educação, nota-se que as atuações dos mecanismos horizontais de controle consistem na verificação da aplicação da lei, caso em que um maior gasto com saúde e educação aumenta a chance de o município cumprir a legislação.

Em outras palavras, o controle horizontal está alinhado ao equilíbrio fiscal, ao passo que estabelece parâmetros para garantir mínimos de investimentos em áreas sociais de saúde e educação. Nesse sentido, o controle horizontal possui como foco a ampliação dos gastos em saúde e educação e redução dos gastos com folha de pagamento, repasse para o poder legislativo e abertura de créditos.

Além disso, o conhecimento técnico, legal, a possibilidade de criar punições sobre a gestão pública e a autonomia dada aos elementos de controle horizontal elevaram sua capacidade de atuação, tornando-se o principal meio de fiscalização das ações públicas (Arantes et al., 2010). Outro fato corresponde ao reforço das legislações fiscais, em especial da Lei de Responsabilidade Fiscal, que aumentou a obrigação dos municípios em cumprir os limites estabelecidos pela legislação, considerando a possibilidade de punição (Araújo, Santos Filho, Gomes, 2015; Cruz \& Afonso, 2018).

Contudo, é importante destacar que a legislação não estabelece critérios qualitativos e de desempenho e, portanto, a avaliação dos mecanismos horizontais está limitada a compreender se a aplicação dos recursos atendeu ao mínimo constitucional. Embora estejam presentes nos relatórios do TCE-MG algumas análises de desempenho, como o cumprimento das metas do Plano Nacional de Educação Básica, esses comentários correspondem apenas a alertas aos gestores públicos, não podendo ser aplicados como fatores de punição. Tal fato se torna uma crítica realizada também por Rocha (2013) nos relatórios do TCE de Santa Catarina, contudo alertam que a análise de benefício-custo dos recursos aplicados cabe à sociedade avaliar e considerar, com maior propriedade, os resultados encontrados.

Assim, de forma a fazer com que os gastos públicos sejam bem geridos, o Controle Social se faz presente, ainda que neste estudo esse aspecto tenha apresentado uma relação negativa. Essa relação reforça o que Smulovitz e Peruzzotti (2000) afirmaram, a respeito de que as instituições do Controle Social modificaram as relações entre a sociedade e a gestão pública, conseguindo maior controle e fiscalização da corrupção, bem como conseguindo depor políticos, tudo na busca por melhorias do gasto público, exercendo cada vez mais influência nas ações do Estado. Por outro lado, ainda falta engajamento da sociedade para fazer com que as deliberações se tornem práticas, como destacam Magalhães e Xavier (2019). Apesar das falhas dos conselhos, ainda assim é reforçado a importância desse ambiente de discussão democrática, como um campo de ocupação do espaço social legitimado (Chasukwa et al., 2014).

A influência dos gastos sociais foi significativa para as três dimensões do desenvolvimento (Saúde, Educação e Emprego e Renda), contudo positiva apenas para a Saúde e negativa para as demais. Tal situação, para a saúde, pode ser explicada pelo fato de que os resultados do investimento na saúde são mais imediatos. Considerando que o foco dos municípios se dá para a atenção primária, com a prevenção da saúde, o investimento para essa área reduz o número de indivíduos que necessitarão de cuidados mais complexos como internações e cirurgias (que são mais custosas aos cofres públicos), amplia o monitoramento à saúde, controla o fluxo de atendimento de saúde, tudo resultando em aumentos mais imediatos para a saúde pública municipal.

Por outro lado, devido aos resultados da educação serem vistos por meio de uma geração, a melhoria de sua qualidade, para ser sensível a indicadores, ocorre em longo prazo. Assim, no curto prazo, os gastos aplicados são tratados como falta de eficiência na aplicação, gerando resultados negativos para o desempenho da educação.

Outro fato pode ser interpretado como ganho de escala, uma vez que as atividades de educação são exercidas em coletivo, de forma que capacitação de professores, ampliação de salas de aula e escolas, por exemplo, afetam um mesmo grupo de indivíduos que são atendidos pelo mesmo professor e mesma sala de aula. Além disso, o resultado da educação, que é o conhecimento, além dos recursos disponíveis, depende 
da interação entre o professor e o aluno. Embora não fosse prevista essa relação negativa de gastos com a educação, ela foi observada por outros autores, como Neduziak e Correia (2017). Esses autores indicaram também a possível captação de ineficiência com gastos em um período curto.

Contudo, quando verificaram o aspecto temporal, Blankenau, Simpson e Tonljanovich (2007) e Mattei, Bezerra e Mello (2018) encontraram que os gastos em educação geram melhorias em sua avaliação. Tais estudos reforçam que os gastos com educação surtem efeito a longo prazo, indicando que a aplicação dos recursos no ano corrente somente surtirá efeitos na educação em períodos futuros.

Para emprego e renda, por sua vez, o crescimento de gastos pode resultar em desequilíbrio das contas públicas e resultar na queda de investimento dentro do município e, consequentemente, na queda de oportunidade de emprego. Por fim, nota-se que o PIB, exceto para o Índice de capacidade, se mostrou significante e positivo para todas as relações, , indicando que quanto maior a atividade econômica no município, maior o desenvolvimento em suas diversas dimensões (saúde, educação e emprego e renda), quanto na ampliação dos gastos per capita, visto que tende a aumentar a receita pública e possibilitar que se realizem investimentos com maior intensidade.

Quanto aos efeitos indiretos (de mediação e de moderação) e diretos (ver Tabela 5), note-se que a Capacidade, moderada pela Alocação, possui efeito positivo para a Saúde, mas negativo para Educação e Emprego e renda, como foi observado na relação geral de Alocação com os indicadores socioeconômicos.

A relação negativa entre capacidade com educação pode ser causada devido à educação de um ano ser um indicativo de capacidades e esforços realizados no passado. Logo, maior investimento comparado à resultados de curto prazo, como no estudo, pode indicar relações negativas. Para tal comprovação, contudo, recomenda-se que seja feita análises com períodos temporais maiores.

Bernardo, Almeida e Nascimento (2020) verificaram ainda que vencimentos e vantagens fixas (elementos relacionados ao corpo burocrático e à capacidade estatal) possuem influencia negativa para a educação, além de não ter encontrado significância para mão-de-obra qualificada. Por outro lado, os autores identificaram que a qualidade da educação é afetada por infraestrutura na educação e investimentos aplicados à saúde, elementos relacionados à um corpo externo não mensurando no presente estudo.

Tabela 5:

Coeficientes de efeitos indiretos (mediação e moderação) e diretos

\begin{tabular}{|c|c|c|c|c|}
\hline  & Direto & Erro Padrão Robusto & Indireto & Erro padrão robusto \\
\hline \multicolumn{5}{|l|}{ Alocação } \\
\hline Capacidade & $0,097^{\star \star}$ & 0,114 & (Apenas direto) & \\
\hline Vertical & (Apenas indireto) & & 0,009 & 0,003 \\
\hline Horizontal & $0,089^{*}$ & 0,016 & $-0,005$ & 0,002 \\
\hline $\mathrm{PIB}$ & $0,349^{\star \star *}$ & 0,030 & 0,004 & 0,003 \\
\hline Social & $-0,130^{\star \star *}$ & 0,011 & $-0,012$ & 0,002 \\
\hline \multicolumn{5}{|l|}{ Saúde 2016} \\
\hline Alocação & $0,170^{\star * *}$ & 0,017 & $-0,051^{* * *}$ & 0,004 \\
\hline Educação 2016 & $0,238^{* * *}$ & 0,103 & (Apenas direto) & \\
\hline Capacidade & (Apenas indireto) & & $0,012^{\star \star}$ & 0,005 \\
\hline Vertical & (Apenas indireto) & & 0,001 & 0,000 \\
\hline Horizontal & (Apenas indireto) & & 0,010 & 0,001 \\
\hline PIB & $0,213^{\star * *}$ & 0,012 & $0,146^{\star * *}$ & 0,007 \\
\hline Social & (Apenas indireto) & & $-0,017^{*}$ & 0,001 \\
\hline \multicolumn{5}{|l|}{ Educação 2016} \\
\hline Alocação & $-0,215^{* * *}$ & 0,008 & (Apenas direto) & \\
\hline Capacidade & (Apenas indireto) & & $-0,021^{*}$ & 0,004 \\
\hline Vertical & (Apenas indireto) & & $-0,002$ & 0,000 \\
\hline Horizontal & (Apenas indireto) & & $-0,018^{*}$ & 0,001 \\
\hline $\mathrm{PIB}$ & $0,438^{\star \star \star}$ & 0,005 & $-0,076^{* * *}$ & 0,002 \\
\hline Social & (Apenas indireto) & & $0,030^{\star *}$ & 0,000 \\
\hline \multicolumn{5}{|c|}{ Emprego e Renda 2016} \\
\hline Alocação & $-0,172^{\star \star \star}$ & 0,014 & $-0,011^{\star \star \star}$ & 0,001 \\
\hline Educação 2016 & 0,052 & 0,081 & (Apenas direto) & \\
\hline Capacidade & (Apenas indireto) & & $-0,018^{* *}$ & 0,007 \\
\hline Vertical & (Apenas indireto) & & $-0,002$ & 0,000 \\
\hline Horizontal & (Apenas indireto) & & $-0,016^{*}$ & 0,001 \\
\hline PIB & $0,593^{\star \star *}$ & 0,010 & $-0,042$ & 0,005 \\
\hline Social & (Apenas indireto) & & $0,026^{\star *}$ & 0,001 \\
\hline \multicolumn{5}{|l|}{ Capacidade } \\
\hline Vertical & 0,097 & & (Apenas direto) & \\
\hline Horizontal & $-0,047$ & & (Apenas direto) & \\
\hline PIB & 0,041 & & (Apenas direto) & \\
\hline Social & $-0,124^{\star \star}$ & & (Apenas direto) & \\
\hline
\end{tabular}

Fonte: dados da pesquisa 
Para emprego e renda, a capacidade municipal pode ser indicativa do esforço de cargos públicos, que tiveram maior investimento em sua carreira, mas possuem remunerações e estabilidade diferentes daquela proveniente da iniciativa privada. Por outro lado, o emprego e renda está relacionado com a economia, assim como indicaram os resultados com relação direta e positiva.

A relação da economia com as condições socioeconômicas se mostrou forte. Para Saúde, foi identificado que o PIB teve efeito indireto, moderado pela Alocação, positivo. Além do efeito indireto em Saúde, houve também efeito direto para essa variável, assim como para Educação e Emprego e Renda. Os coeficientes positivos e fortes do PIB corroboram o estudo de Mendes et al. (2018), que indicou que a economia, mensurada pelo PIB, corresponde a um forte elemento de influência na melhoria do desenvolvimento humano.

\section{Considerações Finais}

O presente estudo teve como objetivo verificar a influência da accountability e da capacidade estatal na alocação dos recursos públicos e no desenvolvimento socioeconômico em municípios brasileiros, considerando o controle horizontal, vertical e social como elementos da accountability. Diante dos resultados apresentados, nota-se que a capacidade estatal do município é um importante instrumento da alocação dos recursos públicos. Sua influência é dada pelo conjunto de elementos que compõem a capacidade, a considerar os elementos políticos, administrativos e burocráticos. Nota-se ainda que a capacidade do município é influenciada diretamente por instrumentos democráticos de controle, sejam por instrumentos eleitorais captados pelo Controle Vertical, sejam por instrumentos de accountability Social, captados pelo Controle Social.

Contudo, embora os instrumentos verticais exerçam influência positiva, possivelmente pela manutenção da estrutura política da capacidade estatal, os instrumentos sociais de controle fornecem influência negativa, podendo ser resultado das diversas demandas apresentadas pela sociedade, que são crescentes, o que pode dificultar cada vez mais a atuação da gestão pública. Além disso, outros fatores podem gerar esse efeito, tais como a própria característica do controle social, que exerce embargos e impedimentos na implementação e investimento de políticas públicas, principalmente visando a qualidade na prestação de serviços e o atendimento à legislação.

Tais resultados reforçam a necessidade do fortalecimento do aparato democrático dentro dos municípios brasileiros, de forma a fomentar a capacidade estatal dos municípios, direcionar recursos e apontar demandas. O Controle Horizontal se mostrou significante somente para influenciar positivamente os gastos sociais. Tendo em vista que os instrumentos de controle horizontal estão interessados no cumprimento da legislação, o aumento dos gastos com saúde e educação amplia a chance do município em cumprir com o estabelecido na Constituição Federal em relação aos gastos sociais.

Por outro lado, o Controle Horizontal se mostrou com influência indireta e negativa sobre as condições socioeconômicas, reforçando a discussão de que, embora apresente o aparato técnico, além da capacidade de realizar vistorias e auditorias, o controle horizontal é limitado a cumprir somente o que está previsto pelas normas legais, reduzindo sua atuação formal com a real transformação do recurso público em algum bem para a sociedade.

Esses resultados ampliam a literatura ao destacar que a accountability em seus três modos de atuação (horizontal, vertical e social) realiza influência na capacidade estatal, tanto em nível de controle quanto em prestação de contas. Ainda, as relações encontradas permitem inferir sobre a importância de cada modelo de accountability sobre tanto na gestão quanto em suas ações. A visão multifacetada da accountability permite observar que suas operações divergem em áreas, com a horizontal focada no aparato técnico, a vertical no campo da eleição e a social dentro dos interesses da sociedade. Essas operações, por outro lado, se completam ao buscar a melhoria dos resultados sociais perpassando pela capacidade estatal e alocação dos recursos.

Destaca, nesse cenário, o papel da capacidade municipal sobre a alocação dos recursos públicos. Tal fato evidencia que todo o esforço da gestão pública é válido para ampliar a melhoria das condições sociais. Mais ainda, diante o modelo sistêmico, é possível inferir que, mais do que válido, é fundamental o papel do Estado como promotor do desenvolvimento socioeconômico, sendo central dentro do cenário de alocação dos recursos públicos. Destaca ainda a influência da educação sobre a saúde, indicando que o desenvolvimento ocorre de forma sistêmica, cujo investimento empregado em uma área irá influenciar outra.

Essa evidência aumenta a responsabilidade do gestor público em ampliar a capacidade de seu corpo burocrático de forma a responder à sociedade sobre aquilo que é de interesse público. Ainda, qualquer desvio de conduta, será avaliado tanto pelo controle horizontal e social (influenciando sobre a alocação dos recursos), quanto ao julgamento da responsabilização por parte do controle horizontal que afeta a capacidade.

A economia saudável representa um importante elemento dentro da construção do desenvolvimento, tendo em vista que afeta tanto os recursos a serem aplicados quanto às condições de saúde, educação e emprego e renda. Isso reforça o cuidado que a administração pública deve ter em criar políticas de incentivo á economia local, que deve ser sustentável na criação e distribuição de riquezas.

Os gastos sociais per capita, como previsto, afetam positivamente o desempenho da saúde pública, 
contudo influenciam negativamente o desempenho da educação. Para a saúde, a influência pode ser devida aos resultados de políticas públicas na saúde surtirem efeito em um prazo menor, com redução de óbitos, de internações e ampliação do acesso a serviços de saúde de atenção básica, que são preventivas e de custos menores que aquelas realizadas de forma curativa.

Por outro lado, a educação é vista como um elemento de geração, cujos resultados da melhoria do acesso surtirão efeito a longo prazo. Nesse sentido, mesmo tomando um período de 1 ano para captar o efeito na educação, os resultados foram negativos, indicando que é necessário um prazo maior para verifica se há benefícios causados pelo investimento nessa área. Contudo, o que se espera é que o resultado de investimentos no ano corrente seja sensível a longo prazo, considerando que seja capaz de interferir na estrutura de conhecimento do aluno. Porém, para tal constatação é necessário que se realize uma verificação de longo prazo.

Quanto a emprego e renda, a elevação dos gastos sociais também teve efeito negativo, o que pode se dever ao crescimento de despesas sem considerar as receitas, o que pode causar desequilíbrio nas contas municipais e desinteressar o investimento de capital privado dentro do município, reduzindo o emprego e renda da população.

Dadas essas limitações do estudo, para pesquisas futuras, recomenda-se a verificação dos efeitos a longo prazo do investimento social sobre a qualidade da educação e melhoria do emprego e renda. É importante ainda que se investigue a relação da proporção do gasto com programas sociais pelo volume de receitas, considerando a manutenção da saúde fiscal do município.

Por fim, o presente estudo mostra a complexidade da gestão pública municipal, destacando a importância da capacidade estatal do município como um interveniente da melhoria das condições sociais. Além disso, destaca a atuação dos mecanismos de controle como forma de buscar o cumprimento da legislação e a boa aplicação dos recursos públicos.

\section{Referências}

Acock, A. C. (2013). Discovering structural equation modeling using. College Station: Stata Press Book.

Alesina, A. F., \& Perotti, R. (1999). Budget Deficits and Budget Institutions. In: Poterba, J. M. Fiscal Institutions and Fiscal Performance. Chicago: University of Chicago Press. 13-36.

Ali, M. U., \& Pirog, M. (2019). Social Accountability and Institutional Change: The Case of Citizen Oversight of Police. Public Administration Review, 79 (3), 411-426. DOI: https://doi.org/10.1111/puar.13055

Arantes, R. B., Loureiro, M. R., Couto, C., \& Teixeira, M. A. C. (2010). Controles democráticos sobre a administração pública no Brasil: Legislativo, tribunais de contas, Judiciário e Ministério Público. In: Loureiro, M. R., Abrucio, F., \& Pacheco, R. Burocracia e política no Brasil. Desafios para o Estado democrático no século XXI. Rio de Janeiro: FGV, 26.

Araújo, A. H. D. S., Santos Filho, J. E. D., \& Gomes, F. G. (2015). Lei de Responsabilidade Fiscal: efeitos e consequências sobre os municípios alagoanos no período 2000-10. Revista de Administração Pública, Rio de Janeiro, 49 (2), 739-759. DOI: http://dx.doi.org/10.1590/0034-7612132652

Asadullah, M. N., \& Savoia, A. (2018). Poverty reduction during 1990-2013: Did millennium development goals adoption and state capacity matter? World Development, 105, 70-82. DOI:

https://doi.org/10.1016/j.worlddev.2017.12.010

Baião, A. L., Cunha, A. S. M. D., \& Souza, F. S. R. N. D. (2017). Papel das Transferências Intergovernamentais na Equalização Fiscal dos Municípios Brasileiros. Revista do Serviço Público, Brasília, 68(3), 583-610. DOI: https://doi.org/10.21874/rsp.v68i3.1406

Bernardo, J. S., Almeida, F. M., \& Nascimento, A. C. C. (2020). Qualidade geral da educação municipal e as influências dos gastos públicos. As políticas públicas para acesso ao ensino superior privado e seus reflexos na qualidade da educação brasileira. Arquivos Analíticos de Políticas Educativas, 28 (23), 1-24. DOI: https://doi.org/10.14507/epaa.28.5054

Blankenau, W. F., Simpson, N. B., \& Tomljanovich, M. (2007). Public Education Expenditures, Taxation, and Growth: Linking Data to Theory. The American Economic Review, 97(2), 393-397. Recuperado de https://www.jstor.org/stable/30034482

Brinkerhoff, D. W., \& Wetterberg, A. (2015). Gauging the Effects of Social Accountability on Services, Governance, and Citizen Empowerment. Public Administration Review, 76(2), 274-286. DOI:

https://doi.org/10.1111/puar.12399 
Cingolani, L. (2013). The State of State Capacity: a review of concepts, evidence and measures. UNUMERIT Working Papers, Maastricht, 53(Working Paper Series on Institutions and Economic Growth IPD WP13), 1-58.

Chasukwa, M, Chiweza, A. L, \& Chikapa-Jamali, M. (2014). Public participation in local councils in Malawi in the absence of local elected representatives - political eliticism or pluralism? Journal of Asian and African Studies, 49(6), 705-720. DOI: https://doi.org/10.1177/0021909613509218

Cruz, C. F. D., \& Afonso, L. E. (2018). Gestão fiscal e pilares da Lei de Responsabilidade Fiscal: evidências em grandes municípios. Revista de Administração Pública, Rio de Janeiro, 52(1), 126-148. DOI: http://dx.doi.org/10.1590/0034-7612165847

Fox, J. A. (2015). Social Accountability: What Does the Evidence Really Say? World Development, 72(3), 346-361. DOI: http://dx.doi.org/10.1016/i.worlddev.2015.03.011

Fukuyama, F. (2004). State-Building: Governance and World Order in the 21st Century. Ithaca: Cornell University Press.

Gaitán, F., \& Boschi, R. R. (2016). Estado, Atores Predominantes e Coalizões para o Desenvolvimento: Brasil e Argentina em perspectiva comparada. In: Gomide, A. D. Á., Boschi, R. R. Capacidades Estatais em Países Emergentes: o Brasil em perspectiva comparada. Rio de Janeiro: Ipea, 473-508.

Gibler, D. M., \& Miller, S. V. (2014). External territorial threat, state capacity, and civil war. Journal of Peace Research, 55(5), 634-646. DOI: https://doi.org/10.1177/0022343314531003

Gomide, A. D. Á., \& Pires, R. R. C. (2014). Capacidades Estatais E Democracia: a abordagem dos arranjos institucionais para análise de políticas públicas. In: Gomide, A. D. Á., Pires, R. R. C. Capacidades Estatais e Democracia: Arranjos institucionais de políticas públicas. Brasília: IPEA, 15 - 28.

Grin, E. J., Nascimento, A. B., Abrucio, F. L., \& Fernandes, A. S. (2018). Sobre desconexões e hiatos: uma análise de capacidades estatais e finanças públicas em municípios brasileiros. Cadernos Gestão Pública e Cidadania, 23(76). DOI: http://dx.doi.org/10.12660/cgpc.v23n76.75417

Grindle, M. S. (1996). Challenging the state: Crisis and innovation in Latin America and Africa. Cambridge, USA: Cambridge University Press.

Guillén, M. F., \& Capron, L. (2016). State Capacity, Minority Shareholder Protections, and Stock Market. Administrative Science Quarterly, 61(1), 125-160. https://doi.org/10.1177\%2F0001839215601459

Hair Jr., J. F. et al. (2009). Análise Multivariada de dados. Porto Alegre: Bookman.

Holzer, M., \& Schwester, R. W. (2011). Public Administration: An introduction. Nova York: M. E. Sharpe.

Huerta, A. R. (2008). Una ruta metodológica para evaluar la capacidad institucional. Política y Cultura, Cidade do México, 30, 119-134.

Justice, J. B., Melitski, J., \& Smith, D. L. (2006). E-Government as an Instrument of Fiscal Accountability and Responsiveness: Do the Best Practitioners Employ the Best Practices? The American Review of Public Administration, 36(3), 301-322. Recuperado de http://arp.sagepub.com/content/36/3/301.abstract

Knutsen, C. H. (2013). Democracy, State Capacity, and Economic Growth. World Development, 43, 1-18. DOI: http://dx.doi.org/10.1016/i.worlddev.2012.10.014

Leon-Moreta, A. (2017). Social Context, Institutional Capacity, and Police Services: A Local Public Economies Perspective. Public Administration Review, 78(2), 270-283. https://doi.org/10.1111/puar.12875

Magalhães, F. G. G. P., \& Xavier, W. S. (2019). Processo Participativo no Controle Social: Um Estudo de Caso do Conselho Municipal de Saúde de Juiz de Fora (MG). REAd. Revista Eletrônica de Administração, 25(1), 179-212.

Marôco, J. (2006). Análise estatística com utilização do SPSS. 6. ed. Lisboa: Edições Sílabo. 
Marôco, J. (2010). Análise de equações estruturais: fundamentos teóricos software e aplicações. Pêro Pinheiro: Reportnumber.

Mattei, T. F., Bezerra, F. M., \& Mello, G. R. D. (2018). Despesas Públicas e o Nível de Desenvolvimento Humano dos Estados Brasileiros: Uma Análise do IDHM 2000 e 2010. RACE, 17(1), 29-54. DOI: https://doi.org/10.18593/race.v17i1.10296

Mendes, Wesley de Almeida, Ferreira, Marco Aurélio Marques, Abrantes, Luiz Antônio, \& Faria, Evandro Rodrigues de. (2018). A influência da capacidade econômica e da formação de receitas públicas no desenvolvimento humano. Revista de Administração Pública, 52(5), 918-934. https://doi.org/10.1590/0034$\underline{761220170004}$

Musgrave, R. A. (1959). The Theory of Public Finance: a study in public economy. New York: McGraw-Hill.

Neduziak, L. C. R., \& Correia, F. M. (2017). Alocação dos gastos públicos e crescimento econômico: um estudo em painel para os estados brasileiros. Revista de Administração Pública, Rio de Janeiro, 51(4), 616632. DOI: http://dx.doi.org/10.1590/0034-7612155177

O'donnell, G. (1994). Delegative democracy? Journal of democracy, 5(1), 55-69. Recuperado de https://muse.jhu.edu/article/225426/summary

Oliveira, L. S. D. De, \& Araújo, A. O. (2019). As despesas públicas municipais como determinante no desenvolvimento humano. Revista Contemporânea de Contabilidade, Florianópolis, 16(38), 87-104. DOI: https://doi.org/10.5007/2175-8069.2019v16n38p87

Pires, R. R. C., \& Gomide, A. D. Á. (2016). Governança e capacidades estatais: uma análise comparativa de programas federais. Revista de Sociologia e Política, Curitiba, 24(58), 121-143. DOI: http://dx.doi.org/10.1590/1678-987316245806

Rogers, M. Z., \& Weller, N. (2014). Income taxation and the validity of state capacity indicators. Journal of Public Policy, Cambridge, 34(2), 183-206. DOI: https://doi.org/10.1017/S0143814X1300024X

Rocha, A. C. (2013). A realização da accountability em pareceres prévios do Tribunal de Contas de Santa Catarina. Revista de Administração Pública, 47(4), 901-925. Recuperado de http://bibliotecadigital.fgv.br/ojs/index.php/rap/article/view/9638/8671

Sabioni, Marjorie, Ferreira, Marco Aurélio Marques, Braga, Marcelo José, \& Almeida, Fernanda Maria de. (2016). Contextos (in)adequados para o engajamento cidadão no controle social. Revista de Administração Pública, 50(3), 477-500. https://doi.org/10.1590/0034-7612153518

Sell, F. F., Sampaio, G. L., Zonatto, V. C. da S., \& Lavarda, C. E. F. (2018). Accountability: uma observação sobre o nível de transparência de municípios. Administração Pública e Gestão Social, 10(4), 248-259. Recuperado de https://periodicos.ufv.br/apgs/article/view/5676

Sen, A. (2010). Desenvolvimento como liberdade. São Paulo: Companhia das Letras.

Silva, A. L. N. D. (2015). Os estados no Suas: uma análise da capacidade institucional dos governos estaduais na assistência social. Revista de Administração Pública, Rio de Janeiro, 49(5), 1167-1192. DOI: http://dx.doi.org/10.1590/0034-7612139292

Smulovitz, C., \& Peruzzotti, E. (2000). Societal Accountability in Latin America. Journal of Democracy, 11(4), 147-158. Recuperado de http://muse.jhu.edu/article/17084

Souza, C. (2017). Modernização do Estado e construção de capacidade burocrática para a implementação de políticas federalizadas. Revista de Administração Pública, Rio de Janeiro, 51(1), 27-45. DOI:

http://dx.doi.org/10.1590/0034-7612150933

Ward, H., Cao, X., \& Mukherjee, B. (2014). State Capacity and the Environmental Investment Gap in Authoritarian States. Comparative Political Studies, 43(3), 309-343. DOI:

https://doi.org/10.1177/0010414013509569 


\section{NOTAS}

\section{AGRADECIMENTOS}

Os autores agradecem à CAPES.

\section{CONTRIBUIÇÃO DE AUTORIA}

Concepção e elaboração do manuscrito: W. A. Mendes. M. A. M. Ferreira

Coleta de dados: W. A. Mendes

Análise de dados: W. A. Mendes. M. A. M. Ferreira

Discussão dos resultados: W. A. Mendes. M. A. M. Ferreira

Revisão e aprovação: M. A. M. Ferreira

\section{CONJUNTO DE DADOS DE PESQUISA}

O conjunto de dados que dá suporte aos resultados deste estudo não está disponível publicamente.

\section{FINANCIAMENTO}

O presente trabalho foi realizado com apoio da Coordenação de Aperfeiçoamento de Pessoal de Nível Superior - Brasil (CAPES) - Código de Financiamento 001.

\section{CONSENTIMENTO DE USO DE IMAGEM}

Não se aplica.

\section{APROVAÇÃO DE COMITÊ DE ÉTICA EM PESQUISA \\ Não se aplica.}

\section{CONFLITO DE INTERESSES}

Não se aplica.

\section{LICENÇA DE USO}

Os Direitos Autorais para artigos publicados neste periódico são do autor, com direitos de primeira publicação para a Revista. Em virtude de aparecerem nesta Revista de acesso público, os artigos são de uso gratuito, com atribuições próprias, em aplicações educacionais, de exercício profissional e para gestão pública. A Revista adotou a licença Creative Commons Atribuição 4.0 Internacional - CC BY NC ND. Esta licença permite acessar, baixar (download), copiar, imprimir, compartilhar, reutilizar e distribuir os artigos desde que com a citação da fonte, atribuindo os devidos créditos de autoria. Nesses casos, nenhuma permissão é necessária por parte dos autores ou dos editores. Autores têm autorização para assumir contratos adicionais separadamente, para distribuição não-exclusiva da versão do trabalho publicada nesta revista (ex.: publicar em repositório institucional ou um capítulo de livro).

\section{PUBLISHER}

Universidade Federal de Santa Catarina. Curso de Ciências Contábeis e Programa de Pós-graduação em Contabilidade. Publicação no Portal de Periódicos UFSC. As ideias expressadas neste artigo são de responsabilidade de seus autores, não representando, necessariamente, a opinião dos editores ou da universidade.

\section{EDITORES}

Carlos Eduardo Facin Lavarda e Suliani Rover

\section{HISTÓRICO}

Recebido em: 09/06/2020 - Revisado por pares em: 11/09/2020 - Reformulado em: 21/09/2020 Recomendado para publicação em: 15/10/2020 - Publicado em: 15/01/2021 